\title{
Construction of a VPN System for Remote Programming and Monitoring of Environmental Parameters for Serving Plant Production in Greenhouses
}

\section{Nguyen Van Dieu \& Ngo Tri Duong}

Faculty of Engineering, Vietnam National University of Agriculture, Hanoi 131000, Vietnam

\begin{abstract}
This article introduces a virtual private network (VPN) system deployed in a $70 \mathrm{~m}^{2}$ operator station and greenhouse at Vietnam National University of Agriculture. The VPN system was not limited by geographical distance and allowed for remote monitoring of environmental parameters, viz. light (10$160001 u x)$, soil moisture $(20-100 \%)$, temperature $\left(20-60^{\circ} \mathrm{C}\right)$, and ambient humidity (30-90\%) with tolerances of $\pm 5 \%$ of the set/measured values. The signals from the sensor system were recorded with a sampling time of 6 seconds. The designed interface made it easy for Vietnamese users. The system was initially established, and tested successfully with Gerbera in the greenhouse. The VPN system allowed for remote programming, stable operation, and no loss of data during the signal collecting process, and allowed users to fully and quickly react when the system crashed or when the user needed to upgrade or maintain the greenhouse system.
\end{abstract}

\section{Keywords}

VPN, monitoring, remote programming

\section{Introduction}

The application of high technology in agricultural production is of great interest in countries with harsh climates and scarce resources. There have been many studies that offer wireless solutions for sensor networks to exchange data or to provide control requests for remote systems such as Li et al. (2010) who introduced

Received: November 23, 2018 Accepted: April 6, 2019

Correspondence to nvdieu@vnua.edu.vn a monitoring system for plants in a greenhouse based on a wireless sensor network and the launching of an automated control system in a greenhouse based on wireless sensor networks using Zigbee (Park et al., 2011). Those studies have been applied in practice but have 
not been yet connected to generate a large network. There have also been several popular PLC (programmable logic controller) applications such as Martin et al. (2016) who managed a blueberry farm and monitoring system using a PLC based on a wireless sensor network; and Sindhu et al. (2016) who used a PLC for the purpose of designing, selecting, controlling, updating, and upgrading greenhouses. The biggest downside of those systems, however, is that they must have direct professional support from the manufacturer when the system commits errors. The direct support can increase the initial investment cost for the user as well as the time it takes to get professional assistance when the system is in operation.

Since 2010, the research and application of hi-tech systems in domestic crop production have been implemented but still on a small scale. An automatic control model was applied to a plant growth house in the area of Ho Chi Minh City in a study by Lam et al. (2012). In addition, research and development of automated monitoring systems for the growth and development processes of greenhouse crops, and applications in the production of high-tech flowers have also been studied (Duong et al., 2016). The above research articles have supported users by using a PLCSIMATIC to control, monitor, and collect information of the systems through a screen interface in the greenhouse. Even so, users must frequently visit the greenhouse to control the systems, especially since if a problem occurs it will not be detected or treated in time if there is no one at the greenhouse. Quy et al. (2016) built an automatic smartphone model that automatically controls and monitors the greenhouse environment through a wireless transmit/receive module and STM microcontroller. The research team just released this model but it has not been applied in practice. In addition, with the use of microcontrollers in practice, the stability and reliability are not high, the rate of damage is high, replacement and program editing are complex, and the ability to upgrade peripheral equipment is limited.

According to the report of Vinh et al. (2014), they developed several multimedia services and monitored production environment parameters on the WIMAX telecommunications network in the Central Highlands. Then, Minh et al. (2015) improved the model and introduced a method for controlling and monitoring environmental parameters on a cloud computing platform via a wireless WIMAX telecommunication network. However, the system is susceptible to bad weather, and nearby radio waves can cause interference, data depletion, or disconnection of the transmission line leading to disruption of services to users. The Northern Electricity Corporation made a plan in 2015 to build a $110 \mathrm{kV}$ TBA electrical substation without human monitoring and a remote controller center by 2020. The scheme uses the IPsec VPN peers protocol as an internal network but it is still undergoing testing. Because of the outstanding advantages of VPNs, in the near future, it is going to become a popular technology.

\section{Materials and Methods}

Planting techniques and plant care, as well as the factors affecting the greenhouse crops, were researched and implemented in the greenhouses and the operator station of Vietnam National University of Agriculture with the web server application PLC S7-1200. The wireless communication network system was implemented with the site to site protocol of the VPN and FPT networks.

\section{Installation of the VPN system}

The layout of the whole system is shown in Figure 1.

Here, the VPN technology required the IP address to be in the 2 LAN (local area network site) which was not the same as the network layer. Two Vigor modems were connected via the internet through the tunnel of the VPN.

The operator station was located at the Vietnam National University of Agriculture. 


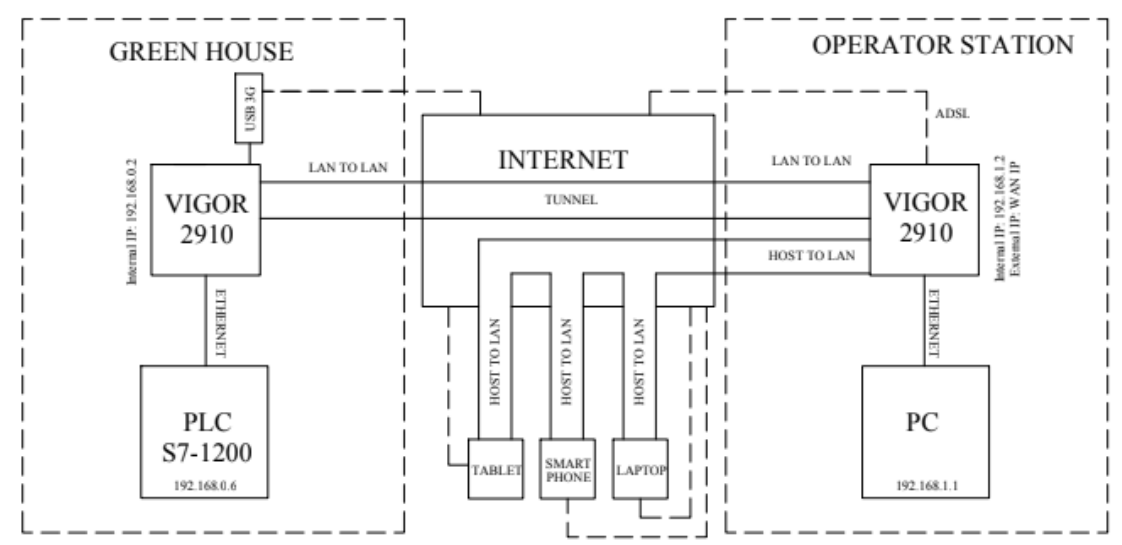

Figure 1. Diagram of the general system and VPN configuration

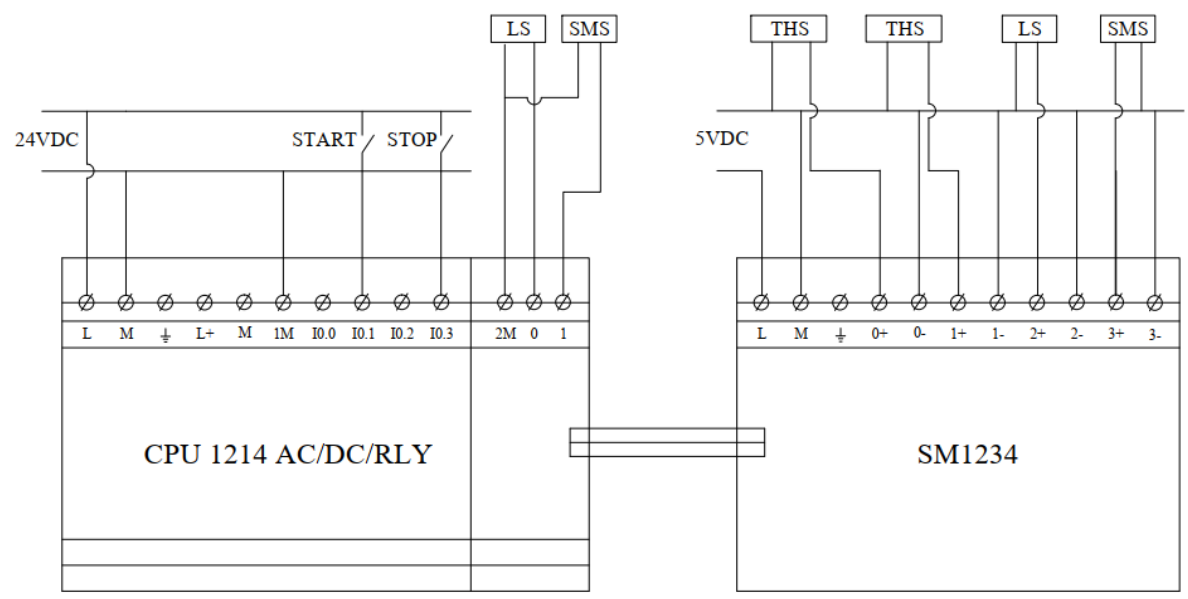

Figure 2. Diagram of the PLC connection and sensor

The computer at the operator station was connected to the Vigor 2910 modem (dial-in) and had to be attached to 1 network layer that the Vigor 2910 modem (dial-in) created. The modem (dial-in) was configured with the FTP network.

The greenhouse was located at the Vietnam National University of Agriculture. The PLC was connected to the Vigor 2910 modem (dialout) with the IP address belonging to the same network layer as the Vigor 2910 modem (dialout). The modem (dial-out) was configured with USB $3 \mathrm{G}$.

The VPN system could connect the LAN to LAN directly through the FPT network or could connect HOST to LAN via an external network to monitor the test environmental parameters in the greenhouse.
Set-up of the systems receiving signals from the sensors

Figure 2 reveals information on the selection and installation of the sensor types to the CPU and expansion module to help collect the parameters of soil moisture, light intensity, temperature, and environment humidity. The signals received were processed through the CPU and then sent to the operator station via the VPN.

\section{Web server application of the PLC for monitoring environmental parameters}

Users could access the webserver interface of the PLC via the name domain. The design and construction of the environmental parameter monitoring interface was based on appropriate requirements that were convenient for Vietnamese people to use. On the basis of the 
parameters measured from the sensors, the data were pushed onto the PLC's webserver interface for remote monitoring by the user.

\section{Running tests and adjustment of the monitoring system}

Implementation of installation, running tests, monitoring, and remote programming of the system were conducted at the greenhouse and the operator station of the Vietnam National University of Agriculture. The tests were completed in order to check and adjust the quality of the system to ensure accuracy and stability at the experimental site. The goals of the tests were to evaluate and analyze the growth environment of crops based on the data of the parameters to improve the system and to develop the best ecosystem for greenhouse crops.

\section{Results and Discussion}

\section{Selection of system installation}

\section{Sensor system}

DHT11 sensors were used to measure the environmental temperature and humidity. The DHT11 sensors had a structure of 4 legs. It used digital interface/serial communication with a 1wire standard. The DHT11 parameters included the tolerances of $1 \% \mathrm{RH}$ and $1{ }^{\circ} \mathrm{C}$. The accuracy of the air humidity measurement at $25^{\circ} \mathrm{C}$ was \pm $4 \% \mathrm{RH}$, at $0-50^{\circ} \mathrm{C} \pm 5 \% \mathrm{RH}$, and the maximum temperature was $\pm 2^{\circ} \mathrm{C}$.
The humidity sensor consisted of a soil humidity sensor and a sensor module. The probe was plugged into the ground to detect moisture; and when the soil moisture reached the set threshold, the DO output moved the status from a low to a high level. When the humidity sensor module was activated, there was a voltage change at the input of the IC LM393.

The light intensive sensor had high accuracy using optical resistors and IC LM393. Optical or photodiode resistors, also known as LDR (light-dependent resistor) or photoresistors, are photoelectric elements made from a polycrystalline semi-conductor material but without a p-n junction semiconductor. As light rays fall onto the photoresistors, they release valuable electrons from the crystal lattice of the semiconductor and cause them to travel like free electrons and increase electrical conductivity, reducing the electrical resistance of the irradiation of light (Dieu, 2008). The LDR fabrication material was a CdS (cadmium sulphide) semiconductor, and very sensitive to the visible light spectrum. In the dark, the LDR photoresistor had an electrical resistance of some $\mathrm{M} \Omega$. When there was light, the electrical resistance decreased to a few hundred $\Omega$. This was a nonlinear electrical resistance. With a measurement range of 10-15000lux, the electrical resistor in the dark was $1 \mathrm{M} \Omega$.

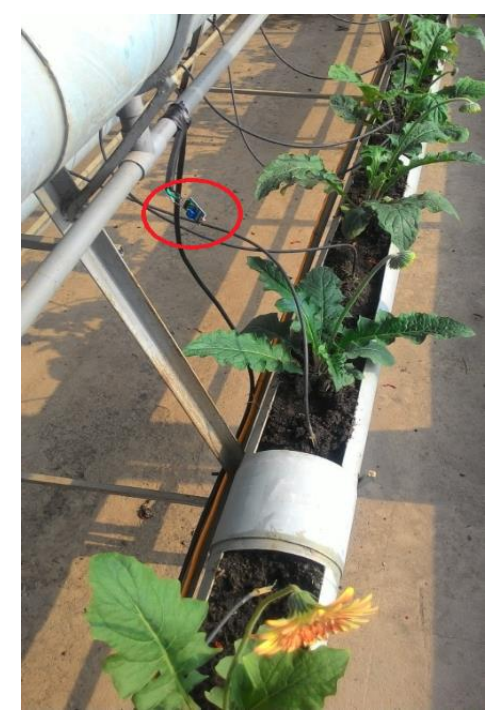

Figure 3. Setting up a light sensor

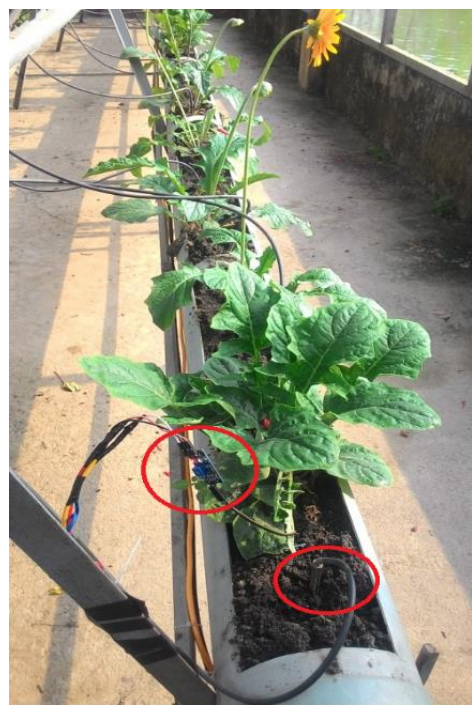

Figure 4. Setting up a soil moisture sensor

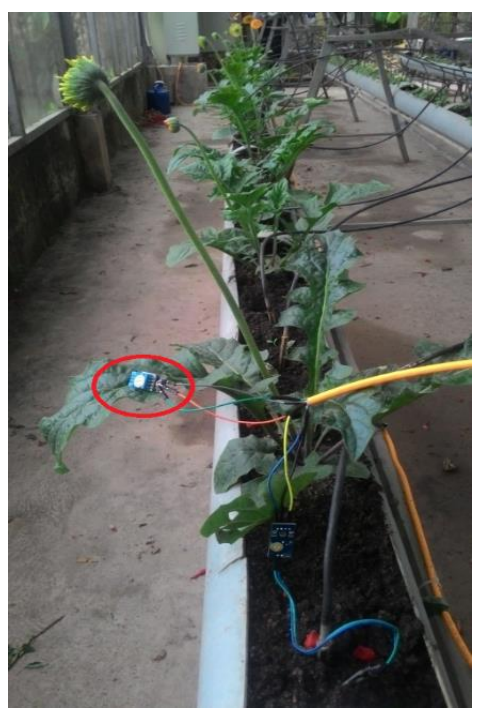

Figure 5. Setting up a temperature and humidity sensor 
PLC S7-1200, expansion module, and vigor 2910

The PLC S7-1200 CPU 1214C AC/DC/RLY (Code 214-1BG31-0XB0) consisted of four basic components: processor, memory, power supply, and interface in-output. The CPU 1214C AC/DC/RELAY was integrated locally with the $14 \mathrm{DI} / 10 \mathrm{DO} / 2 \mathrm{AI}$. The CPU $1214 \mathrm{C}$ had a physical size of $110 \times 100 \times 75 \mathrm{~mm}$.

The SM 1234 analogue module (Code 2344HE32-0XB0) was the same extension module of the S7-1200 PLC. The SM 1234 module production code 6ES7234-4HE32-0XB0 had $4 \mathrm{AI} / 2 \mathrm{AO},+/-10 \mathrm{~V}, 14 \mathrm{BIT} 0(4)-20 \mathrm{~mA}$, and definition of 13 BIT.

The Vigor 2910 had 4 LAN ports, one WAN port, and one USB port for the $3 \mathrm{G}$ modem. The Vigor 2910 can load from 20 to 30 devices and at the same time support the transmission line up to $35 \mathrm{Mbps}$ and support the USB modem with HSDPA standard that can reach up to $1 \mathrm{Mbps}$ of a $3 \mathrm{G}$ mobile phone network system. The main WAN port of 10/100BaseT Ethernet connected to the Internet via an ADSL modem.

\section{Connection of the VPN system}

\section{VPN LAN to LAN}

Here, the authors group performed a ping to the Vigor modem (dial-out) via the LAN to LAN. The sending of several ICMP information packets from the computer connected to the Vigor (dial-in) at the operator station via a VPN transmission line to a Vigor (dial-out) modem that received and responded to the signal indicated that the connection of the VPN LAN to LAN through two Vigor modems was successful (Figure 6A). Figure 6B shows the receipt and response from the PLC in the greenhouse to the operator station via the VPN. The Ping to the IP PLC was successful (Figure 6B).

\section{VPN Host to LAN}

The Host to LAN connection test was set up on a $3 \mathrm{G}$ enabled smartphone named "Green House 1". The connection system was quite stable, and the test was held for about 20 minutes, providing the user enough time to monitor the entire operation of the environment in the greenhouse (Figures 7A and 7B).

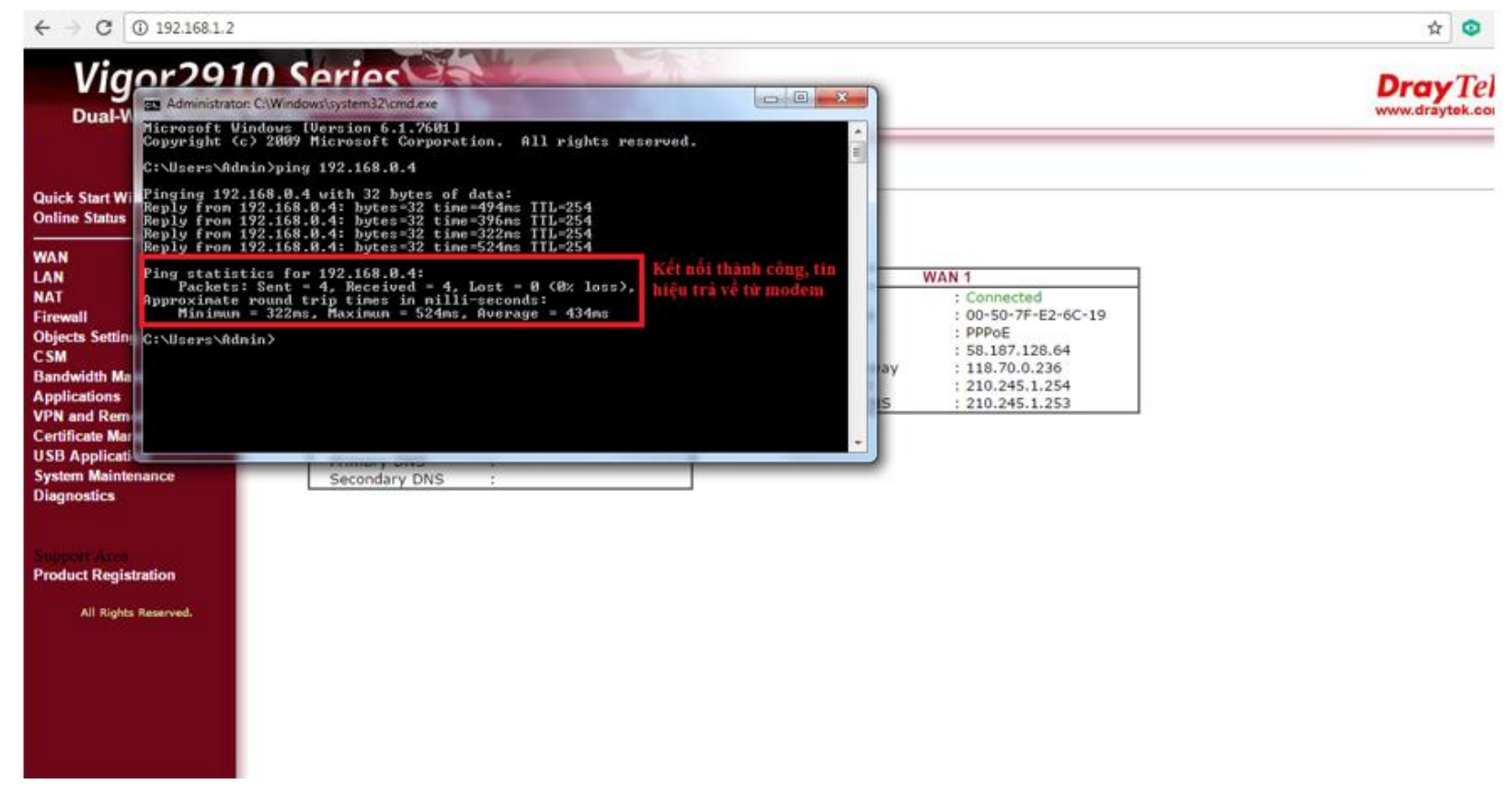

Figure 6A. Vigor program output confirming successful data transmission to the dial-out modem 


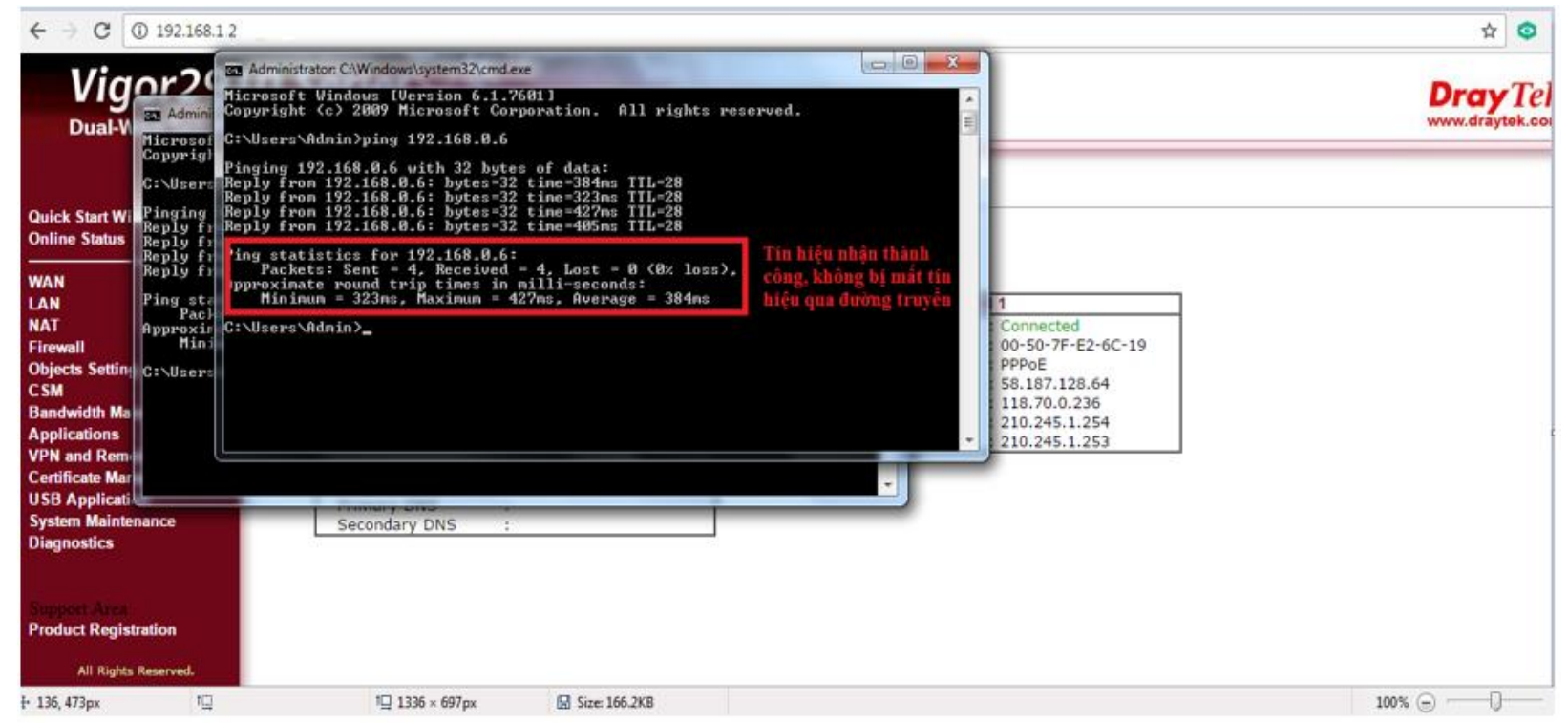

Figure 6B. Vigor program output confirming successful data transmission to the IP PLC in the greenhouse

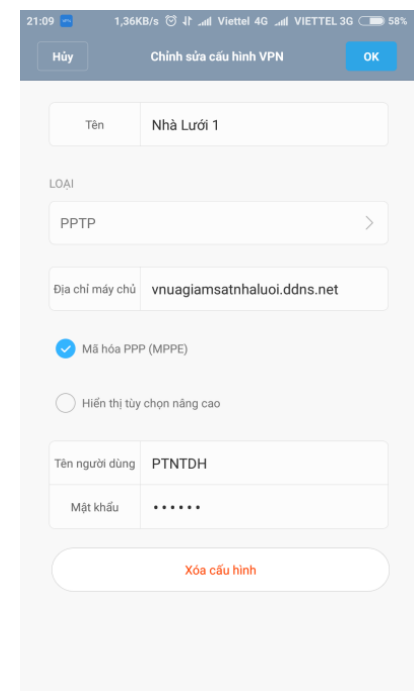

Figure 7A. Smartphone display for setting up the VPN

\section{TIA with PLC}

\section{Connect TIA to PLC}

The TIA connection on the computer at the operator station with the PLC at the greenhouse was performed in the form of the LAN to LAN. When using TIA software on a LAN we could go online to a PLC on another LAN. The successful connection is shown in Figure 8.

\section{Remote programming}

When connecting, going online or otherwise connecting successfully to the PLC

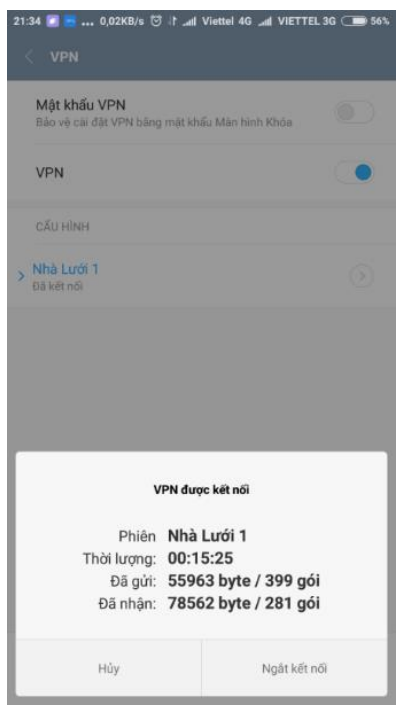

Figure 7B. Smartphone display confirming a successful VPN connection

via the VPN, the programming proceeded as normal. Figure 9 shows how to successfully load the TIA program onto the PLC via the VPN. The program loading time was stable, and there were no data loss or errors during program loading.

\section{Monitoring of environmental parameters via VPN}

\section{Monitoring results from sensors}

Below are some pictures of the signals measured from the sensors on April 28, 2018

Vietnam Journal of Agricultural Sciences 
in the greenhouse at Vietnam National University of Agriculture. With a 6s sampling time, the system received continuous signals from the sensors. The red line represents the signal of sensor 1 , and the green line is the signal received by sensor 2 .

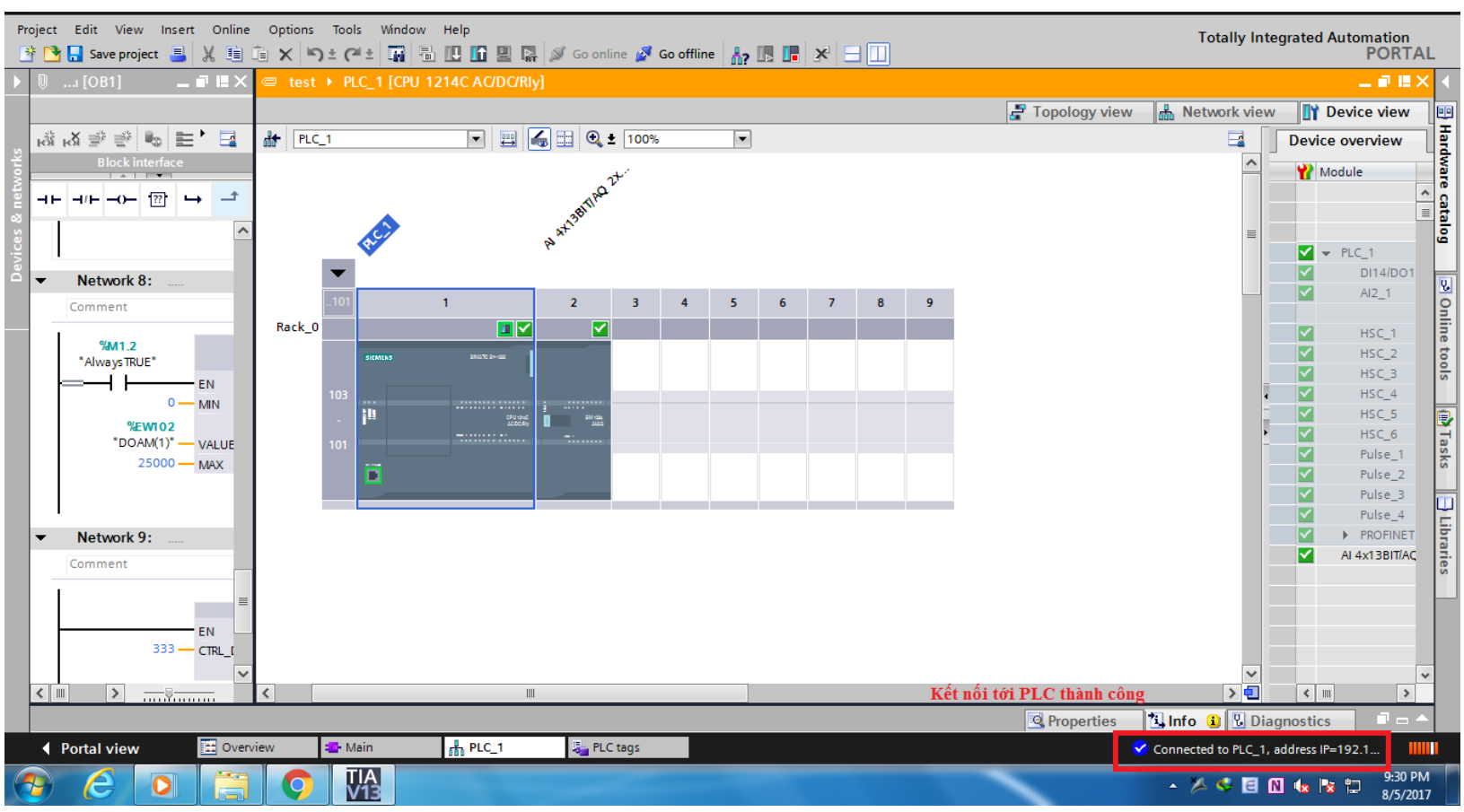

Figure 8. TIA program display allowing for the management of the PLC from the operating station

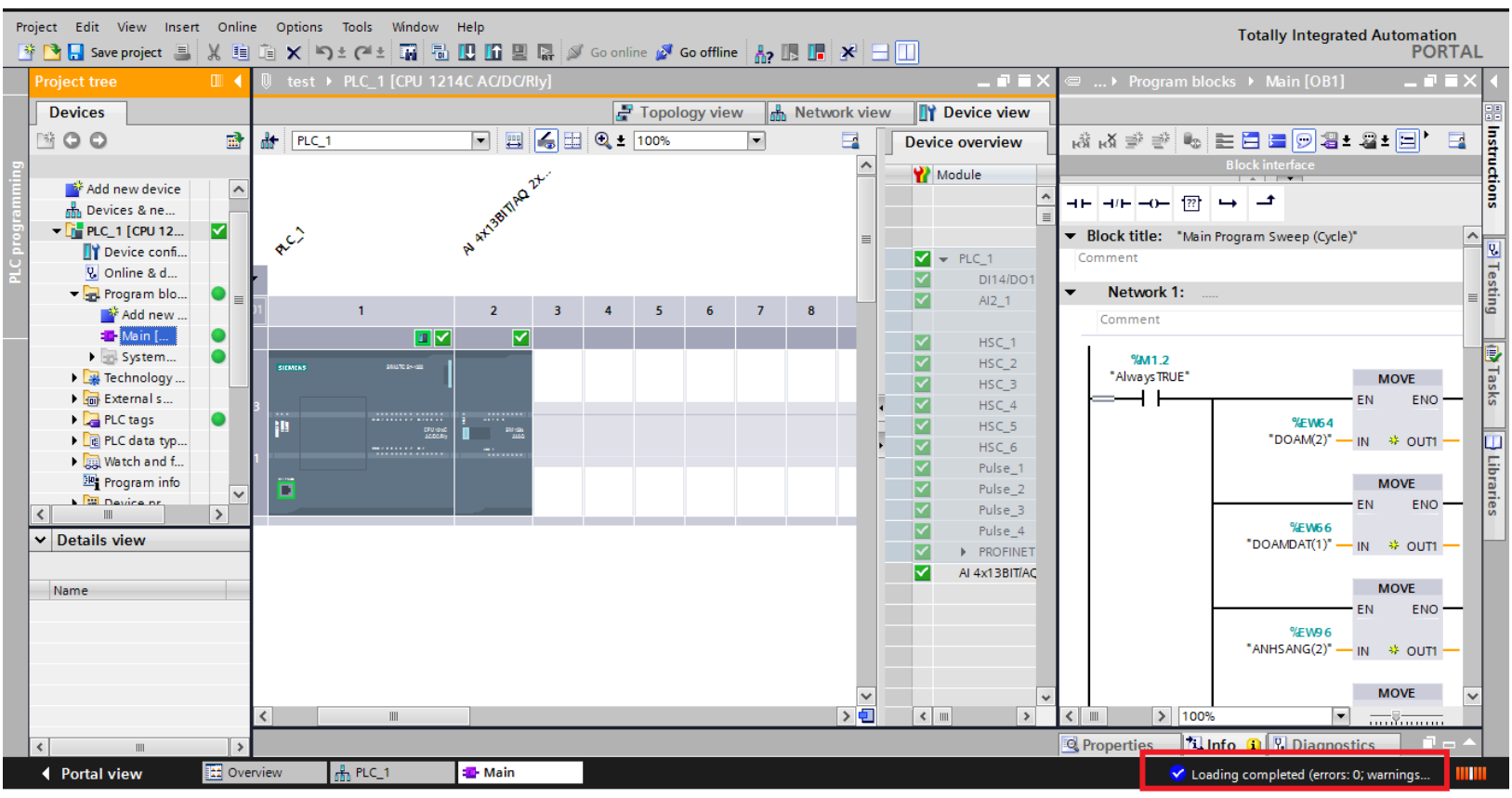

Figure 9. Remote programming for PLC 
Soil moisture monitoring signals (Figures 10 A-D):

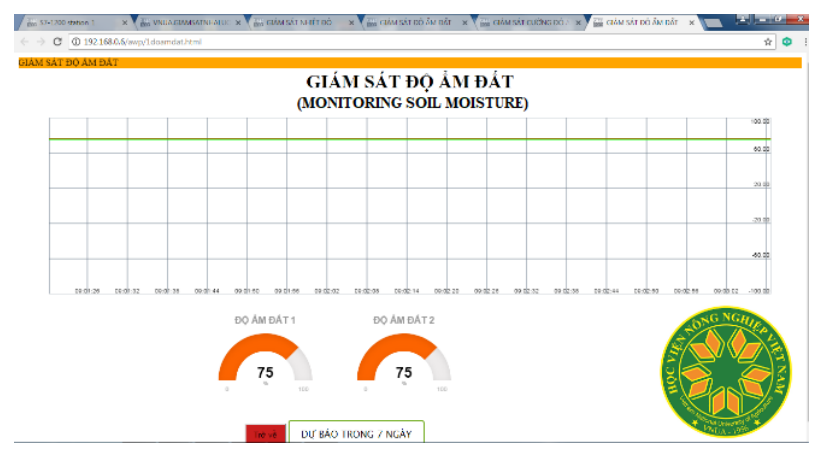

Figure 10A. Soil moisture monitoring signal at 9 am

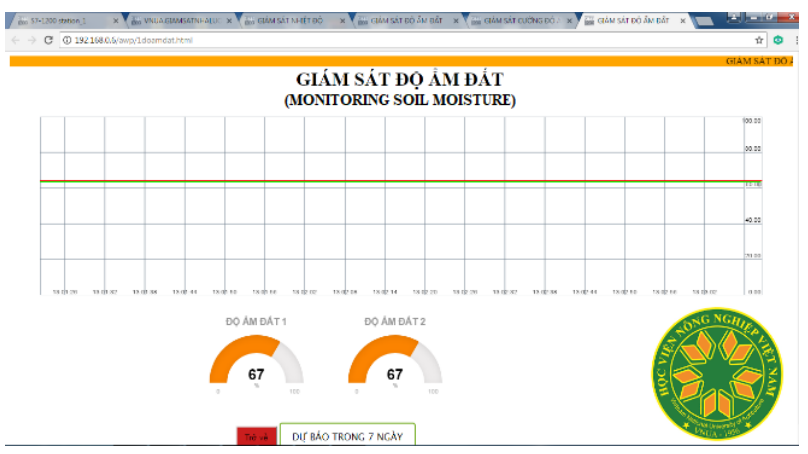

Figure 10B. Soil moisture monitoring signal at $1 \mathrm{pm}$

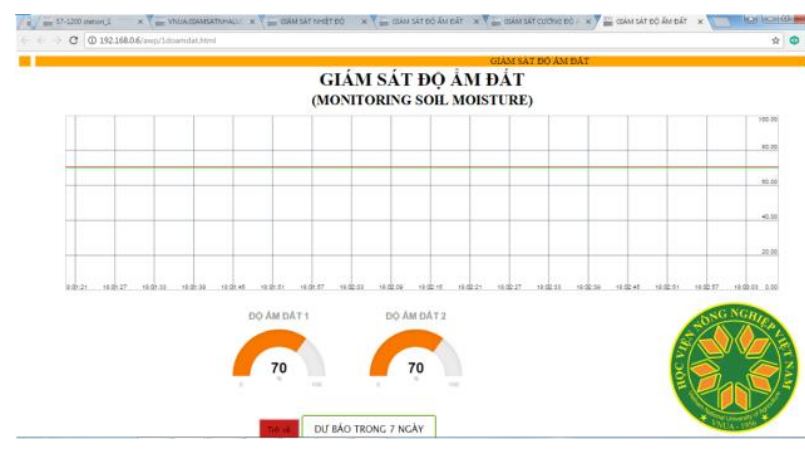

Figure 10C. Soil moisture monitoring signal at $6 \mathrm{pm}$

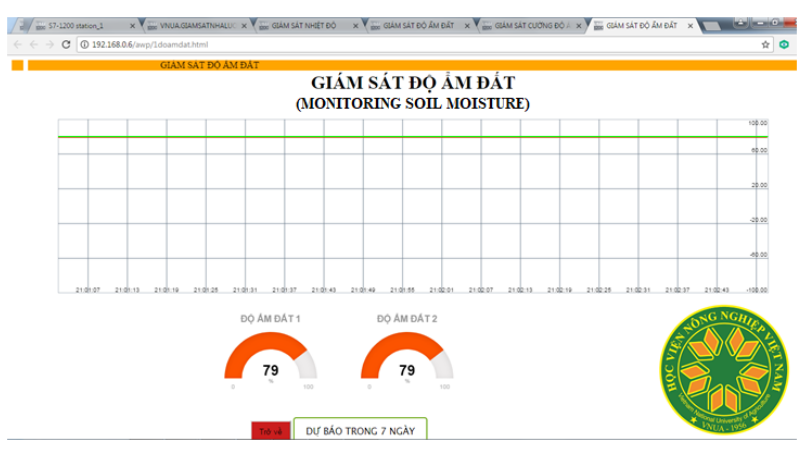

Figure 10D. Soil moisture monitoring signal at $9 \mathrm{pm}$

Light intensity monitoring signals (Figures 11 A-D):

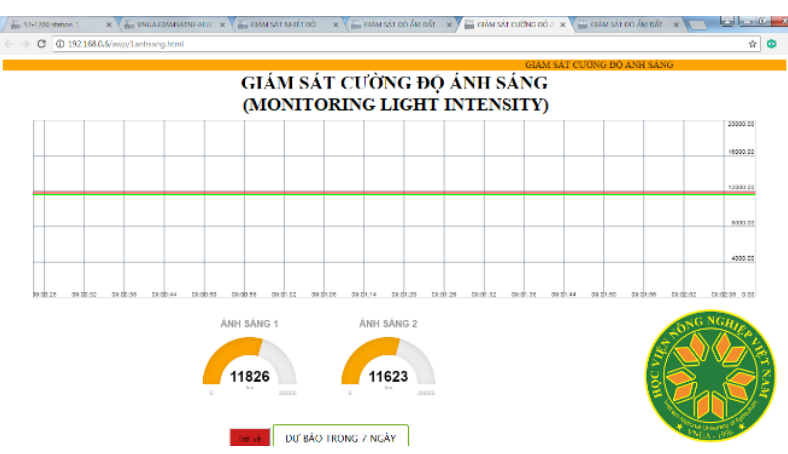

Figure 11A. Light intensity monitoring signal at 9 am

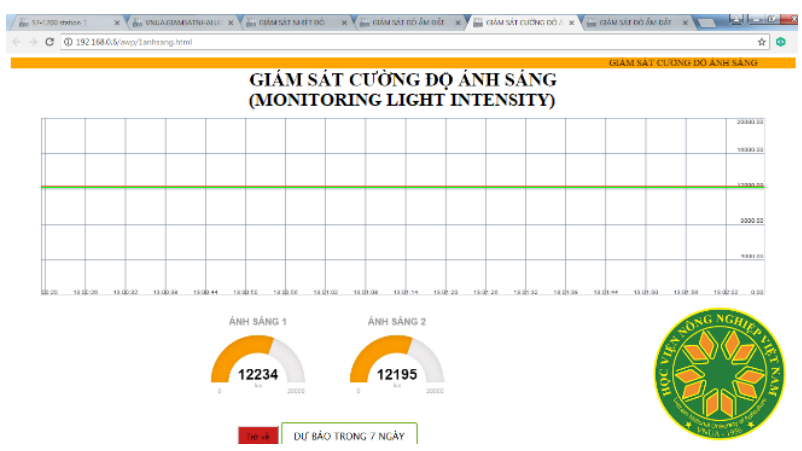

Figure 11B. Light intensity monitoring signal at $1 \mathrm{pm}$ 


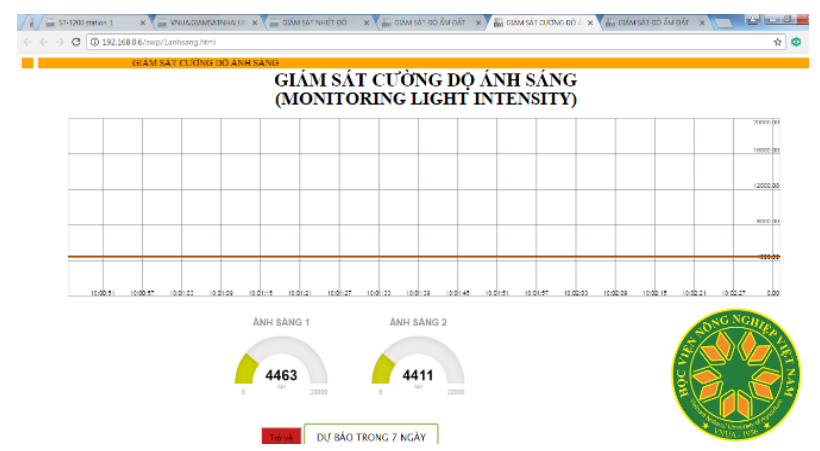

Figure 11C. Light intensity monitoring signal at $6 \mathrm{pm}$

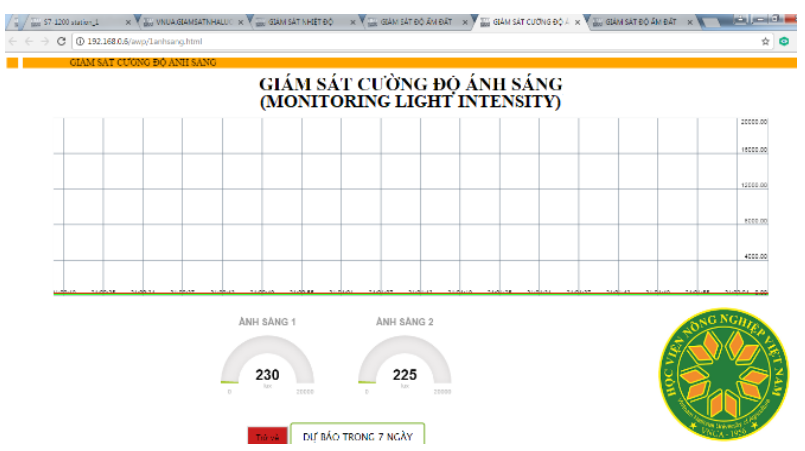

Figure 11D. Light intensity monitoring signal at $9 \mathrm{pm}$

Environmental humidity monitoring signals (Figures 12 A-D):

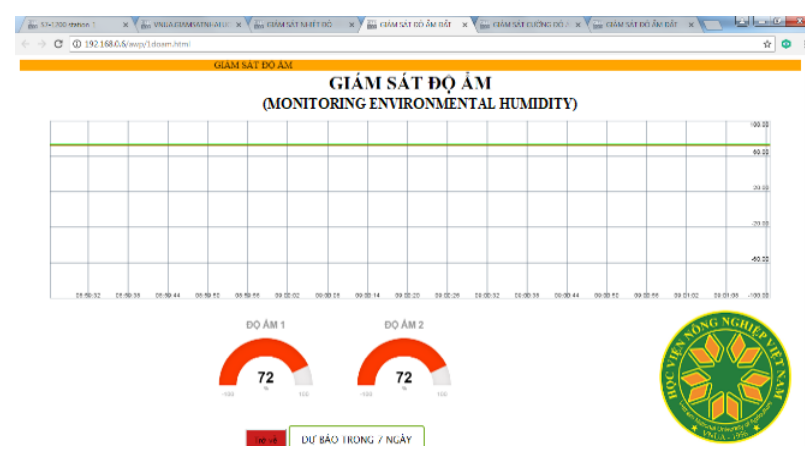

Figure 12A. Environmental humidity monitoring signal at 9 am

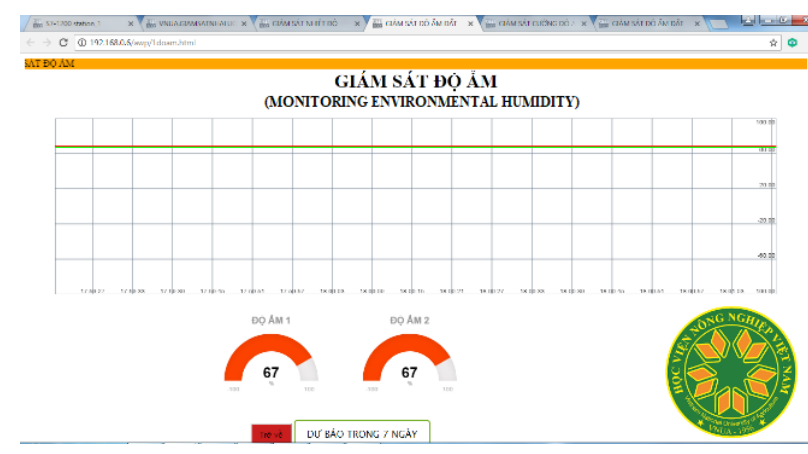

Figure 12C. Environmental humidity monitoring signal at $6 \mathrm{pm}$

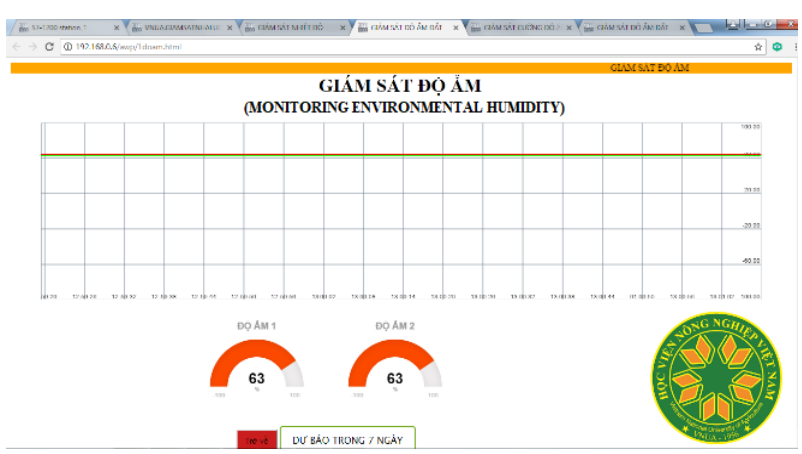

Figure 12B. Environmental humidity monitoring signal at $1 \mathrm{pm}$

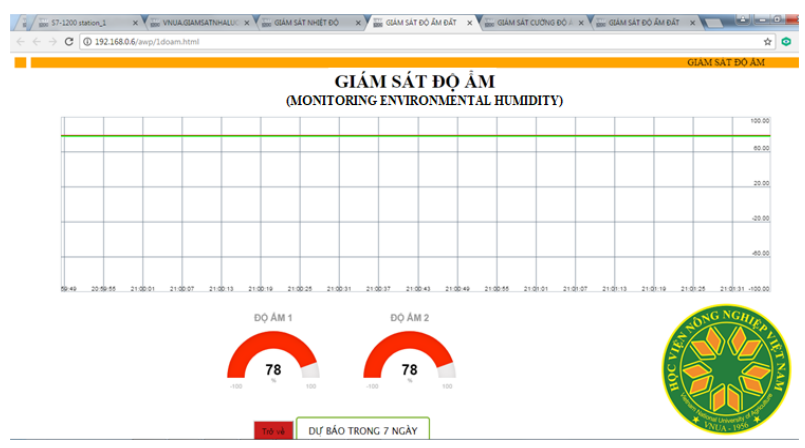

Figure 12D. Environmental humidity monitoring signal at $9 \mathrm{pm}$ 
Environmental temperature monitoring signals (Figures 13 A-D):

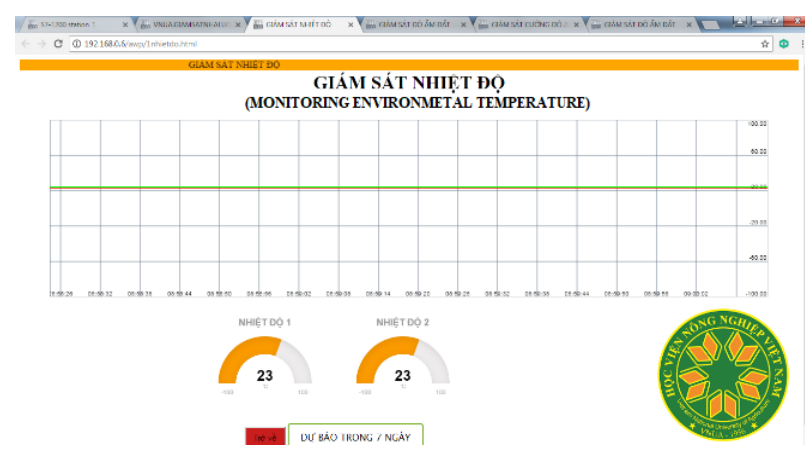

Figure 13A. Environmental temperature monitoring signal at 9 am

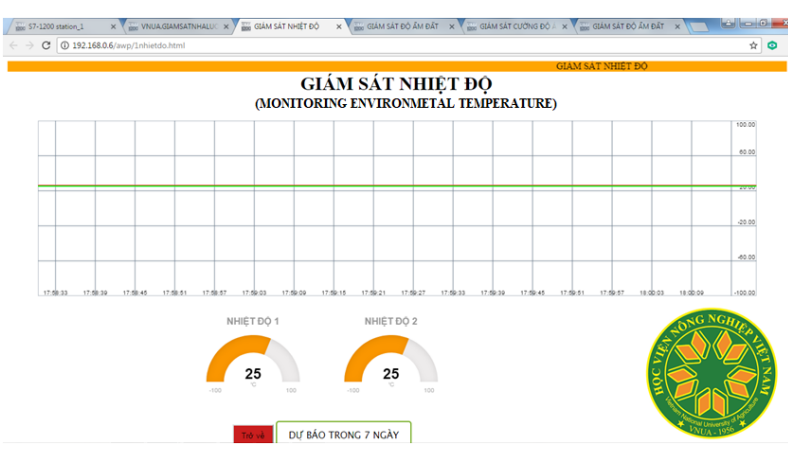

Figure 13C. Environmental temperature monitoring signal at $6 \mathrm{pm}$

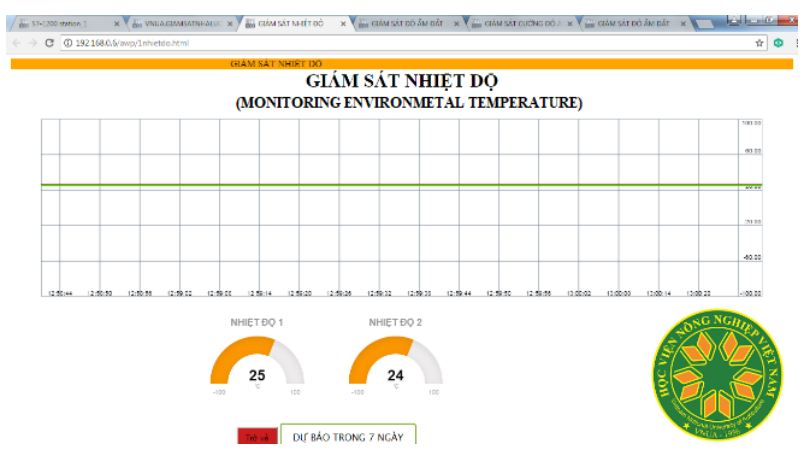

Figure 13B. Environmental temperature monitoring signal at $1 \mathrm{pm}$

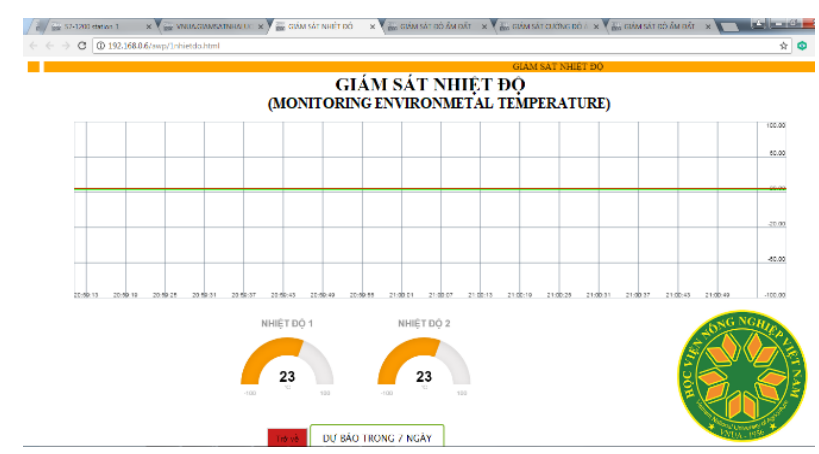

Figure 13D. Environmental temperature monitoring signal at $9 \mathrm{pm}$

Table 1. Misjudged parameters of the soil moisture measurement results in a covered greenhouse at Vietnam National University of Agriculture (April 28, 2018)

\begin{tabular}{lcccccc}
\hline Time of day & $\begin{array}{c}\text { Sensor value } 1 \\
(\%)\end{array}$ & $\begin{array}{c}\text { Measurement } \\
\text { equipment } \\
\text { value } 1(\%)\end{array}$ & $\begin{array}{c}\text { Relative error } \\
(\%)\end{array}$ & $\begin{array}{c}\text { Sensor value } \\
2(\%)\end{array}$ & $\begin{array}{c}\text { Measurement } \\
\text { equipment } \\
\text { value 2 (\%) }\end{array}$ & $\begin{array}{c}\text { Relative error } \\
(\%)\end{array}$ \\
\hline 09:00 a.m. & 75 & 74.6 & 0.54 & 75 & 75.1 & 0.13 \\
09:15 a.m. & 73 & 73.9 & 1.22 & 73 & 73.8 & 1.08 \\
09:30 a.m. & 74 & 74.4 & 0.54 & 74 & 74.6 & 0.80 \\
09:45 a.m. & 73 & 73.9 & 1.22 & 72 & 73.3 & 1.77 \\
13:00 p.m. & 67 & 67.3 & 0.45 & 67 & 67.4 & 0.59 \\
13:15 p.m. & 66 & 66.7 & 1.05 & 66 & 66.6 & 0.90 \\
13:30 p.m. & 66 & 66.8 & 1.20 & 66 & 66.4 & 0.60 \\
13:45 p.m. & 65 & 65.9 & 1.37 & 65 & 65.8 & 1.22 \\
18:00 p.m. & 70 & 70.3 & 0.43 & 70 & 70.2 & 0.28 \\
18:15 p.m. & 70 & 70.4 & 0.57 & 70 & 70.2 & 0.28 \\
18:30 p.m. & 71 & 71.2 & 0.28 & 71 & 71.3 & 0.42 \\
18:45 p.m. & 72 & 71.9 & 0.14 & 72 & 72.2 & 0.28 \\
21:00 p.m. & 79 & 79.5 & 0.63 & 79 & 79.6 & 0.75 \\
21:15 p.m. & 80 & 80.2 & 0.25 & 80 & 80.3 & 0.37 \\
21:30 p.m. & 80 & 80.2 & 0.25 & 80 & 80.3 & 0.37 \\
21:45 p.m. & 79 & 79.6 & 0.75 & 78 & 79.5 & 1.89 \\
\hline
\end{tabular}


Table 2. Misjudged parameters of the light intensity measurement results in a covered greenhouse at Vietnam National University of Agriculture (April 28, 2018)

\begin{tabular}{lcccccc}
\hline Time of day & $\begin{array}{c}\text { Sensor value } 1 \\
\text { (lux) }\end{array}$ & $\begin{array}{c}\text { Measurement } \\
\text { equipment value } \\
\text { 1 (lux) }\end{array}$ & $\begin{array}{c}\text { Relative error } \\
(\%)\end{array}$ & $\begin{array}{c}\text { Sensor value } \\
2 \text { (lux) }\end{array}$ & $\begin{array}{c}\text { Measurement } \\
\text { equipment value } \\
\text { 2 (lux) }\end{array}$ & $\begin{array}{c}\text { Relative error } \\
(\%)\end{array}$ \\
\hline 09:00 a.m. & 11826 & 11811.8 & 0.12 & 11623 & 11811.3 & 1.59 \\
09:15 a.m. & 11563 & 11563.4 & 0.00 & 11563 & 11563.2 & 0.00 \\
09:30 a.m. & 11234 & 11234.5 & 0.00 & 11234 & 11234.5 & 0.00 \\
09:45 a.m. & 11765 & 11723.4 & 0.35 & 11758 & 11723.6 & 0.29 \\
13:00 p.m. & 12234 & 12212.3 & 0.18 & 12195 & 12212.1 & 0.14 \\
13:15 p.m. & 12453 & 12453.8 & 0.01 & 12453 & 12453.4 & 0.00 \\
13:30 p.m. & 12345 & 12345.7 & 0.01 & 12345 & 12345.8 & 0.01 \\
13:45 p.m. & 12643 & 12593.9 & 0.39 & 12598 & 12593.7 & 0.03 \\
18:00 p.m. & 4463 & 4413.9 & 1.11 & 4411 & 4413.8 & 0.06 \\
18:15 p.m. & 4425 & 4425.9 & 0.02 & 4425 & 4425.9 & 0.02 \\
18:30 p.m. & 4463 & 4463.5 & 0.01 & 4463 & 4463.3 & 0.01 \\
18:45 p.m. & 4429 & 4399.2 & 0.68 & 4408 & 4399.4 & 0.20 \\
21:00 p.m. & 230 & 225.7 & 1.91 & 225 & 226.2 & 0.53 \\
21:15 p.m. & 235 & 237.7 & 1.14 & 235 & 239.6 & 1.92 \\
21:30 p.m. & 225 & 228.4 & 1.49 & 225 & 230.1 & 2.22 \\
21:45 p.m. & 245 & 249.1 & 1.65 & 234 & 239.9 & 2.46 \\
\hline
\end{tabular}

Table 3. Misjudged parameters of the environmental humidity measurement results in a covered greenhouse at Vietnam National University of Agriculture (April 28, 2018)

\begin{tabular}{lcccccc}
\hline Time of day & $\begin{array}{c}\text { Sensor value } 1 \\
(\%)\end{array}$ & $\begin{array}{c}\text { Measurement } \\
\text { equipment value } \\
1(\%)\end{array}$ & $\begin{array}{c}\text { Relative error } \\
(\%)\end{array}$ & $\begin{array}{c}\text { Sensor value } \\
2(\%)\end{array}$ & $\begin{array}{c}\text { Measurement } \\
\text { equipment value } \\
2(\%)\end{array}$ & $\begin{array}{c}\text { Relative error } \\
(\%)\end{array}$ \\
\hline 09:00 a.m. & 72 & 71.5 & 0.70 & 72 & 71.5 & 0.70 \\
09:15 a.m. & 71 & 71.5 & 0.70 & 71 & 71.5 & 0.70 \\
09:30 a.m. & 71 & 71.5 & 0.70 & 71 & 71.5 & 0.70 \\
09:45 a.m. & 72 & 71.5 & 0.70 & 72 & 71.5 & 0.70 \\
13:00 p.m. & 63 & 63.1 & 0.16 & 63 & 63.2 & 0.32 \\
13:15 p.m. & 63 & 63.1 & 0.16 & 63 & 63.2 & 0.32 \\
13:30 p.m. & 62 & 62.9 & 1.43 & 62 & 62.6 & 0.96 \\
13:45 p.m. & 62 & 62.9 & 1.43 & 62 & 62.6 & 0.96 \\
18:00 p.m. & 67 & 67.7 & 1.03 & 67 & 67.6 & 0.89 \\
18:15 p.m. & 67 & 67.7 & 1.03 & 67 & 67.7 & 1.03 \\
18:30 p.m. & 67 & 67.7 & 1.03 & 67 & 67.7 & 1.03 \\
18:45 p.m. & 68 & 68.1 & 0.15 & 68 & 68.2 & 0.29 \\
21:00 p.m. & 78 & 78.2 & 0.26 & 78 & 78.4 & 0.51 \\
21:15 p.m. & 77 & 77.8 & 1.03 & 77 & 77.9 & 77.9 \\
21:30 p.m. & 77 & 77.8 & 1.03 & 77 & 78.4 & 1.16 \\
21:45 p.m. & 78 & 78.1 & 0.13 & 78 & 0.51 \\
\hline
\end{tabular}


Optimization of chlorogenic acid extraction from green coffee beans using response surface methodology

Table 4. Misjudged parameters of the environmental temperature measurement results in a covered greenhouse at Vietnam National University of Agriculture (April 28, 2018)

\begin{tabular}{lcccccc}
\hline Time of day & $\begin{array}{c}\text { Sensor value } 1 \\
\left({ }^{\circ} \mathrm{C}\right)\end{array}$ & $\begin{array}{c}\text { Measurement } \\
\text { equipment value } \\
1\left({ }^{\circ} \mathrm{C}\right)\end{array}$ & $\begin{array}{c}\text { Relative error } \\
(\%)\end{array}$ & $\begin{array}{c}\text { Sensor value } \\
2\left({ }^{\circ} \mathrm{C}\right)\end{array}$ & $\begin{array}{c}\text { Measurement } \\
\text { equipment value } \\
2\left({ }^{\circ} \mathrm{C}\right)\end{array}$ & $\begin{array}{c}\text { Relative error } \\
(\%)\end{array}$ \\
\hline 09:00 a.m. & 23 & 23.8 & 3.36 & 23 & 23.8 & 3.36 \\
09:15 a.m. & 24 & 24.2 & 0.83 & 24 & 24.1 & 0.41 \\
09:30 a.m. & 24 & 24.3 & 1.23 & 24 & 24.2 & 0.83 \\
09:45 a.m. & 24 & 24.6 & 2.44 & 24 & 24.5 & 2.04 \\
13:00 p.m. & 25 & 25.2 & 0.79 & 24 & 24.9 & 3.61 \\
13:15 p.m. & 25 & 25.5 & 1.96 & 25.5 & 25.5 & 0.00 \\
13:30 p.m. & 26 & 26.1 & 0.38 & 26 & 26.1 & 0.38 \\
13:45 p.m. & 27 & 27.1 & 0.37 & 27 & 27.2 & 0.74 \\
18:00 p.m. & 25 & 25.3 & 1.19 & 25 & 25.2 & 0.79 \\
18:15 p.m. & 24 & 24.8 & 3.23 & 24 & 24.7 & 2.83 \\
18:30 p.m. & 24 & 24.6 & 2.44 & 24.5 & 24.6 & 0.41 \\
18:45 p.m. & 24 & 24.5 & 2.04 & 24 & 24.4 & 1.64 \\
21:00 p.m. & 23 & 23.1 & 0.43 & 23 & 23.2 & 0.86 \\
21:15 p.m. & 22.4 & 22.5 & 0.44 & 22.5 & 22.6 & 22.6 \\
21:30 p.m. & 22.4 & 22.3 & 0.45 & 22.5 & 21.5 & 0.44 \\
21:45 p.m. & 21 & 21.8 & 3.67 & 21 & 0.44 \\
\hline
\end{tabular}

The environmental parameters in a covered greenhouse at Vietnam National University of Agriculture (April 28, 2018) show that the signals measured from the sensors sent to the operator station were relatively stable and had errors within the allowed range (Tables 1-4). The standard sampling devices used here were similar to the study by Duong et al. (2016).

The results received from the sensors through the VPN show a reliable signal, which allowed the user to master the system as desired. Signal transmission through the VPN was stable, and no signs of loss of transmission or weak signals due to external factors at the greenhouse of Vietnam National University of Agriculture were detected.

\section{Conclusions}

The sensor parameters were recorded with a sampling time of 6 seconds, and the visual expression interface made it easy for the Vietnamese users to safely and quickly monitor the wireless parameters at the limits allowed for light (10-16000lux), soil moisture (20-100\%), temperature $\left(20-60^{\circ} \mathrm{C}\right)$, and ambient humidity (30-90\%) with tolerances of $\pm 5 \%$ of the measured values.

Improving the system and fixing random incidents is essential to deal with the everchanging complexity of the environment. In particular, dealing with unusual situations or upgrading changes to the system need to be strengthened. Therefore, the development of remote monitoring features and remote programming applying VPN technology allows users to react completely and quickly when the system crashes or users need help from the outside.

\section{Acknowledgments}

We would like to thank the staff and students of the Faculty of Engineering, Vietnam National University of Agriculture, for their great contributions to the completion of this research. 


\section{References}

Dieu D. T. (2008). Curriculum measurement sensor technology \& control. Publishing House of Industrial University of HCM City. 70 (in Vietnamese).

Duong N. T. \& Dieu N. V. (2016). Design and manufacture of data collection system on parameters affecting growth and development of gerbera plants grown in greenhouse. Vietnam Journal of Agricultural Sciences. 14(3): 477-490 (in Vietnamese).

Lam N. N., Minh D. Q., Thinh T. C. \& Nhuong P. H. (2012). The model of the automated greenhouse used for HoChiMinh City's area. Journal of Automation Today. Retrieved from http://automation.net.vn/Nghien-cuu-Khoahoc/Mo-hinh-nha-trong-cay-voi-dieu-khien-tudong-ung-dung-tai-khu-vuc-Thanh-Pho-Ho-ChiMinh.html on May 11, 2018 (in Vietnamese).

Li X., Cheng X., Yan K. \& Gong P. (2010). A monitoring system for vegetable greenhouse based on a wireless sensor network. Sensors. 10: 89638980.

Martin N. S., Calado M. R. A., Pombo J. A. N. \& Mariano S. J. P. S. (2016). Blueberries field irrigation management and monitoring system using PLC based control and wireless sensor network. 2016 IEEE $16^{\text {th }}$ International Conference on Environment and Electrical Engineering (EEEIC).

Minh P. N., Phuong N. T., Vinh T. Q., Hoang H. D. \& Thap
P. H. (2015). Method monitor and control environment parameters on cloud computing over WIMAX wireless communication network. Proceedings of the 3rd National Conference on Control and Automation VCCA-2015. Publisher of Natural Science and Technology (in Vietnamese).

Park D., Kang B., Cho K., Shin C., Cho S. \& Park J. (2011). A study on greenhouse automatic control system based on wireless sensor network. Wireless Personal Communications. 56(1): 117-130.

Quy D. X., Dat T. T. \& Quang P. T. A. (2016). Smartphone automatically monitor and control the greenhouse environment via the ESP8266-ESP01 wifi transmitter/receiver module and the STM32F103C8T6 microcontroller. Journal for Science and Technology Information Quang Binh. 2: 44-48 (in Vietnamese).

Sindhu P. S., Divya L. R., Vasuki S. \& Rakesh R. (2016). Glass house horticulture using PLC. Journal of Biometrics and Bioinformatics. 8(9): 239-242.

Vinh T. Q., Tuan D. A., Chung N. D., Long N. T., Liem C. N., Minh P. N., Phuong N. T., Giang P. T., Anh P. Q., Hung N. N., Tung V. D., Duc D. V., Sinh V. T. \& Truong T. M. (2014). Research and development of some multimedia services and monitoring the environmental parameters of production on the WIMAX network in the Central Highlands. Topic TN3/C07 belonging to the Statelevel scientific and technological program (in Vietnamese). 